\title{
Employing Rhetorical Theory in Design Education Practice
}

\author{
SUSANNA KELLY ENGBERS ${ }^{1}$
}

1. Kendall College of Art and Design, Ferris State University, Grand Rapids, Michigan, USA

SUGGESTED CITATION: Engbers, S.K. “Rhetorical Theory in Design Education Practice.” Dialectic, 2.1 (2018): pgs. 81-95. DOI: http://dx.doi.org/10.3998/dialectic.14932326.0002.105

\section{Abstract}

Intersections between the disciplines of rhetoric and design, though well-articulated by scholars in those areas, generally remain more in the realm of theory than practice. This article presents a strategy for integrating rhetorical theory into the university-level classroom to support the processes of student designers (particularly those in visual communications, interaction design, and user experience design). Practice in the art of rhetoric will help such students to both analyze visual, verbal, and material texts (i.e., anything from products to posters to persuasive essays to front porches) as species of discourse and create more successful texts themselves. One fundamental tool to advance students' work in design (as well as in writing and other communicative arts) is the rhetorical triangle; it provides students with a developed, systematic theory and corresponding lines of inquiry to help them achieve their most rhetorically savvy, intelligent work. In addition, an understanding of the rhetorical triangle illuminates one of the most vital intersections between design and the humanities. 


\section{Employing Rhetorical Theory in Design Education Practice}

SUSANNA KELLY ENGBERS

\section{Introduction}

For this issue of Dialectic, which invites conversation of "issues operating at the intersection of design and the humanities," I offer a discussion of rhetoric. Knowledge of principles and practices from this ancient humanistic discipline can help students - especially those in the areas visual communications, interaction design, and user experience design - use rhetoric's systematic approach when analyzing the work of others and when creating their own work. Although scholars such as Richard Buchanan, David Kaufer, Brian Butler, and others have analyzed at length the relationship between rhetoric and design, such connections are often constructed more for use by the researcher-scholar in the field and less for use by the instructor and student in the classroom. To address this deficiency, I offer here some practical strategies to help design students understand and effectively employ key rhetorical theories and concepts in their study and practice.

\section{Rhetoric's Theoretical Connections with Design}

In contemporary popular usage, the word rhetoric often carries pejorative connotations - "hate rhetoric," "empty rhetoric," "mere rhetoric" — yet over its long history the term has generally been defined more favorably. For example, Aristotle described it as "the faculty of discovering in any particular case all of the available means of persuasion." Other Classical rhetoricians presented various alternatives: for example, focusing on the character of the speaker (for 
1

Foss, S., Foss, K., \& Trapp, R. Contemporary Perspectives on Rhetoric, 2nd ed. Prospect Heights, IL, USA: Waveland Press, 1985, p. 14 .

2

Kaufer, D., \& Butler, B. Rhetoric and the Arts of Design. Mahway, N], USA: Erlbaum, 1996, p. 18.

3

Corbett, E. \& Connors, R.

Classical Rhetoric for the Modern

Student, 4th ed. New York, NY, USA: Oxford UP, 1999, p. 1.

4

Buchanan, R. “Declaration by Design: Rhetoric, Argument, and Demonstration in Design Practice." Design Issues, 2.1 (1985): p. 108. it was, of course, initially only an oral art), Quintilian defined rhetoric as the "good man speaking well." Cicero presented rhetoric as "speech designed to persuade." Modern scholars have offered other definitions such as "an action human beings perform when they use symbols for the purpose of communicating with one another." "In Rhetoric and the Arts of Design, David Kaufer and Brian Butler put forth an uncommon but provocative definition, maintaining that rhetoric is "the control of events for an audience." ${ }^{2}$ Edward Corbett and Robert Connors' definition is perhaps the most direct and intelligible for a modern audience: "the art or the discipline that deals with the use of discourse...to inform or persuade or motivate an audience." 3 "Discourse" may refer not only to spoken and written communication but also to visual, material, and hybrid forms-everything from campaign speeches to newspaper editorials, websites, clothing, film documentaries, architecture, and other designed objects. And like designed objects, spaces, systems, communities, and experiences, rhetorical texts are almost developed and deployed in light of those who will listen to, read, view, and/or interact with them. Given its age as a discipline, rhetoric may seem less relevant than more modern methods of inquiry, but the categories of rhetorical analysis provide an adaptable, productive system for students to use in analyzing and creating all manner of communicative texts.

To be sure, the potential for fertile practical connections between the disciplines of rhetoric and design has been articulated in the theoretical scholarship. For example, Richard Buchanan has argued that rhetoric is the architectonic art for all design. Buchanan explains that rhetoric is the "art that organize[s] the efforts of [the design arts] giving order and purpose to production." "He points to rhetoricians' abilities to invent, organize, and present not just words but also material objects to audiences. He notes that traditionally, a rhetorical argument involved a speaker who was "seek[ing] to provide the audience with the reasons for adopting a new attitude or taking a new course of action." He adds that:

"with the rise of technology in the twentieth century, the remarkable power of man-made objects to accomplish something very similar has been discovered. By presenting an audience of potential users with a new product - whether as simple as a plow or a new form of hybrid seed corn, or as complex as an electric light bulb or a computer-designers have directly influenced the actions of individuals and 
communities, changed attitudes and values, and shaped society in surprisingly fundamental ways.” ${ }^{5}$

In other words, when we sit in hotel rooms that interior designers or architects have created, use the bath products industrial designers or consumer product developers have invented, and work at the tables furniture designers have designed, we are shaped in similar ways — and perhaps even more strongly — as we are shaped by the verbal arguments we encounter. He suggests that "the designer, instead of simply making an object or thing, is actually creating a persuasive argument that comes to life whenever a user considers or uses a product as a means to some end." ${ }^{6}$ In Rhetoric and the Arts of Design, Kaufer and Butler share Buchanan's goal of relating design and rhetoric more closely, yet they focus more strictly on the idea of designing with words rather than looking more widely at multimodal rhetoric, as Buchanan does. Kaufer and Butler seek to re-present a theory of rhetoric as design and to understand rhetoric as a "type of productive knowledge." As such, they argue for rhetoric as a "member in full of the family of design arts," akin to architecture and engineering, similar because of their complexity, pragmatic objectives, and contingency, to cite just a few parallels. ${ }^{7}$ And in her more recent article on design rhetoric, Annina Schneller points out that the rhetoricity of designed visual objectsas opposed to written texts - is frequently difficult to discern, partly because visual "language" is almost always more implicit than explicitly expressed verbal language:

5

Ibid, p. 93. 6

Buchanan, R. “Declaration by Design: Rhetoric, Argument, and Demonstration in Design Practice." Design Issues, 2.1 (1985): p. 96.

\section{7}

Kaufer, D., \& Butler, B. Rhetoric and the Arts of Design. Mahway, N], USA: Erlbaum, 1996, p. xvi.

8

Schneller, A. “Design Rhetoric: Studying the Effects of Designed Objects." Nature and Culture, 10.3 (2015), p. 335.
"While there is an explicit content to any normal uttered sentence, the 'content' of an armchair or lemon squeezer is of a rather implicit nature. What is more, spoken and written language usually have a linear and temporal structure, which is why rhetorical effects can be created by contrasting, stressing, or repeating linguistic elements over time. The 'reading' process of designed objects is guided to a lesser extent than that of a printed text. Designed things mostly generate effects of contrast, stress, or repetition within the spatial arrangement of a formal whole present at one time." 8

As Schneller points out, given their tendency toward the indirect rather than the direct, discerning the rhetorical qualities of designed objects is hardly a straightforward exercise. In addition to Buchanan, Schneller, Kaufer and Butler, 
9

Barnard, M. Graphic Design and Communication. London, UK: Routledge, 2005.

10

Davis, M. Graphic Design Theory. New York, NY, USA: Thames \& Hudson, 2012. scholars in graphic design have contributed to a greater appreciation for the rhetorical nature of design. In Graphic Design as Communication, for example, Malcolm Barnard examines the constructions and communication of meaning through graphic design, using rhetoric as one among many critical lenses. ${ }^{9}$ And, in Graphic Design Theory, Meredith Davis presents various communication models from the school of communications theory, noting their underappreciated role in the creation and critique of designed objects and texts. ${ }^{10}$ Despite the fact, however, that the theoretical connections between rhetoric and design are clear to these and many other faculty and scholars whose work is rooted in these respective areas, effectively operationalizing the practical connections between them often proves elusive for design faculty and students.

Developing an awareness of texts - written, oral, visual, material, and hybrid - as being fundamentally communicative poses a challenge for students in rhetoric and design studio classes alike. As a faculty member with a background in rhetoric and composition teaching at a college of art and design, I have long been curious about how to exploit the potentially rich connections between the humanities and art/design in my own classroom and across the college. I began my own education about the teaching and learning going on in the studio classrooms at my college of art and design by turning to my faculty colleagues in these areas. I asked a dozen of them to write about how they invited their students to analyze their designs as rhetorical texts - i.e., as texts that respond to the exigencies of the particular situations for which they were created. When I studied the language of the responses, I noticed that three concepts recurred far more than others - namely the ideas of branding, reaching the client/user, and working on a problem/solution. For example, regarding branding, an interior design faculty member noted that, among the projects she taught in her undergraduate classrooms in a given academic year, her "hospitality project and office environment project" best illustrated an emphasis on transmitting the brand messaging of a specific company. She noted that the design must "work in conjunction with its 'mission' and communicate the goals/ethics/business practices of the company-creative/open/sleek/fun/cool, etc." She pointed to examples of the physical design of Google's or Apple's office spaces that “embody the philosophies" of those companies. Regarding the focus that is often placed on understanding the goals and social or economic biases of a particular user or audience in graphic design, a faculty member from this area said: "We talk about [how] communication design must be 'user-centered' to be effective, because design 


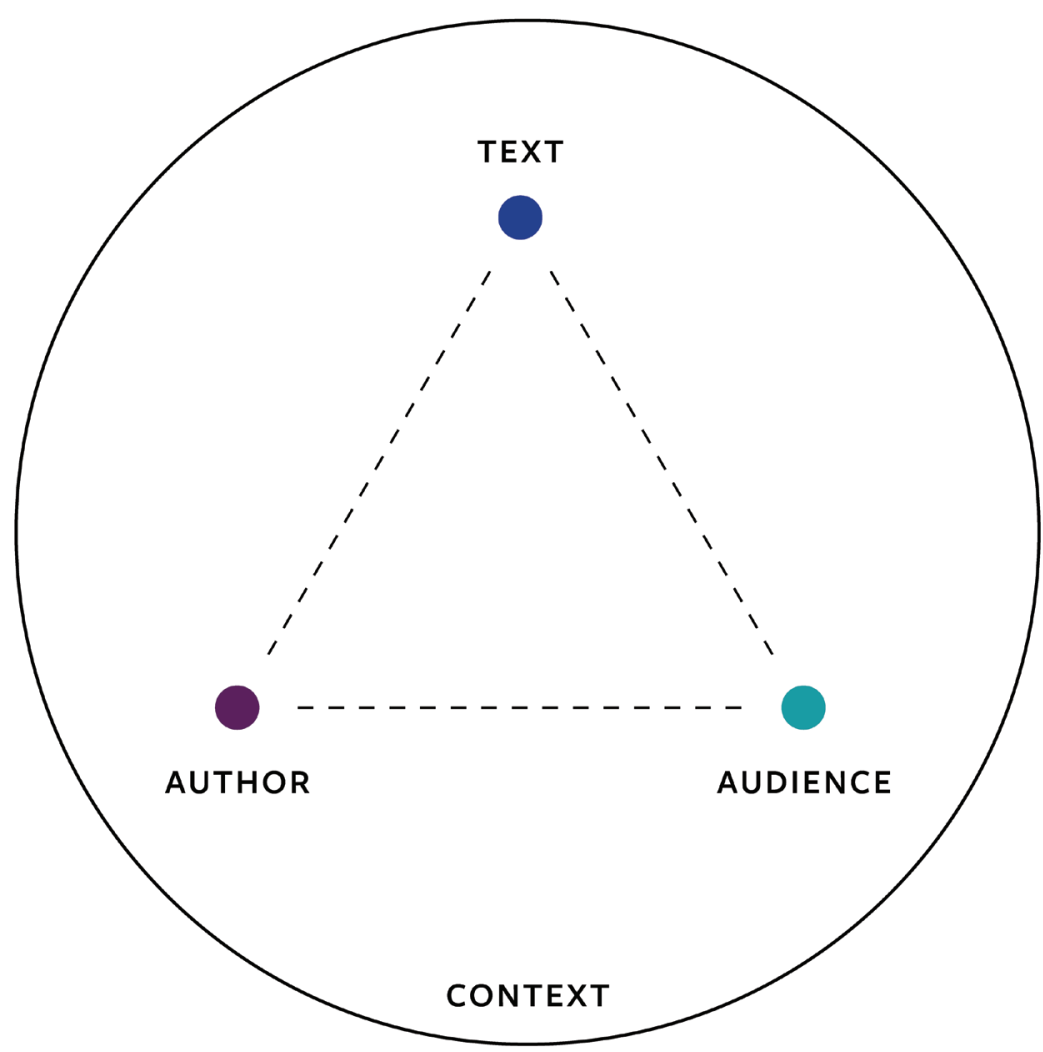

FIGURE 1: The Rhetorical Triangle

for the sake of design and not people is just art.” And on the idea of problem/solution, one industrial design faculty member put it this way: "At its core, the design process is focused on identifying a problem and creating a solution." I recognize that there is a wide body of scholarship in and around all of these areas that add necessary nuance and sophistication to these fundamental ideas that guide how design processes are framed and taught, particularly at the undergraduate level. My faculty colleagues' responses to my fairly casual question elicited appropriately casual responses, but what became most compelling to me as I continued to pose this question was the way in which the comments I received quickly resolved themselves into three basic, practical categories of text, sender, and audience, which are quite familiar to those of us who teach rhetoric and writing.

\section{The Rhetorical Triangle}

In the fields of rhetoric and writing, we refer to those three basic categories as the main elements of the "rhetorical triangle," a term coined by James 


\begin{abstract}
11
Kinneavy, J. A Theory of Discourse: The Aims of Discourse. Englewood Cliffs, NJ, USA: Prentice Hall, 1971. 12
\end{abstract} Davis, M. Graphic Design Theory. New York, NY, USA: Thames \& Hudson, 2012, pgs. 14-31.
Kinneavy, well-known rhetorician and author of A Theory of Discourse (1971) among other works. ${ }^{11}$ Kinneavy developed an image (similar to the one presented here) that could be used as a visual metaphor for a rhetorical (or "communication") situation.

This model presents the relationship between writer, audience, and text, as well as the surrounding context. It points to the ways in which writer, audience, and text (or creator, viewer/user, and object, to recast these in terms more appropriate to the analysis of visual and/or material objects and their relative effects) necessarily affect one another and guide how and why a given object is created and interpreted as it is. For example, a speech on gun control (a text) is necessarily different (either in its creation or its interpretation) when given to gun owners than when presented to peace activists (audience). And a monument designed by Maya Lin (a well-known writer/creator), for example, for a specific situation or occasion also "reads" differently to viewers than one designed by a designer or an artist freshly graduated from college and, as such, who is unknown to the design or the art world. It is an image that now appears commonly in many texts on the study of composition and rhetoric; students in writing and speech classes at both the high school and university levels would likely see this image reproduced quite frequently. Examples of such visual models abound, but some of the most notable include the Shannon-Weaver 1949 Mathematical Model, which is a linear model that depicts a message coming from an information source and going to an encoder, a channel, a decoder, and then a destination; Schramm's 1954 Model of Communication, which is a circular model that also maps a message from an encoder to a decoder; and structural linguist Roman Jakobson's 1960 model of interpersonal verbal communication, which considers the context, contact, addresser, and addressee of a message in an inter-connected manner. These models are wellknown to many scholars in visual communication and interaction design. In Graphic Design Theory, for example, Meredith Davis outlines a number of these models, noting their centrality for theorists and practitioners in these areas of design. ${ }^{12}$ The specific strategies that I outline below, all of which are based on the rhetorical triangle, can help instructors make them even more central, and more useful, in the education of design students studying to enter these professional disciplines.

Though certainly not the most detailed of the models, the rhetorical triangle is imbued with an elegant simplicity, making it well-suited for students to recall and deploy; further, it corresponds neatly to Aristotle's artistic appeals 
of ethos, pathos, and logos. Aristotle, and the many rhetoricians who would pattern themselves after him, focused on persuasive discourse, which he maintained was affected through three kinds of "proofs" (pistis): ethical (appeals to the sender's character); pathetic (appeals to audience's emotions); and logical (appeals to reason). Aristotle referred to these proofs as "artistic," highlighting the idea that they could be generated via the productive art of rhetoric, unlike the "inartistic" or "extrinsic" proofs (e.g., expert or witness testimony, statistics, and the like) that were simply gathered and deployed by the sender/speaker, and not generated, or "invented," through rhetoric. Through the careful generation and deployment of appropriate appeals, the rhetorician stood a greater chance of getting his audience to assent to his line of argument. It is wholly fitting that the appeals dubbed "artistic" are those that so nicely bridge the gap between the humanities and artful discipline of design.

\section{Practical Strategies to Bridge the Gap}

The feedback that I received from the design faculty I questioned in the Art and Design College within which I teach indicated that they emphasize teaching the principal aspects of the traditional rhetorical triangle: namely, (1) a focus on developing or understanding the branding (image, personae, etc.) of the organization being served (ethos), (2) a focus on understanding clients' and users' feelings (pathos), and (3) a concern for ensuring that clients understand the logical advantages associated with the product/design itself (logos). They tended, however, not to implement these appeals in their respective classrooms in a systematic way. Equipping students with a basic system gives them a valuable, easily recalled tool to use as their educational experiences progress. In the design classroom, an awareness of the intersection between design and rhetoric might chiefly be useful in two ways. First, as a means to methodically probe the ways in which communication operates implicitly, and second, as a means to encourage students to look past the immediate effects that a given designed artifact or system appears to have on them as its maker, so that they can examine the medium- and long-term effects that these artifacts or systems might invite or facilitate among a broad cross section of audiences or users in various contexts.

I would stop short of urging an investigation such as that which Schneller undertakes in her study of "design rhetoric," which partly seeks to determine design rules. Using a "triangulation of researchers" to "eliminate in-

dividual bias in effect ascription" (p. 341), Schneller attempts to, as she puts it, 
Schneller, A. “Design Rhetoric:

Studying the Effects of Designed objects." Nature and Culture, 10.3 (2015): pgs. 333-356.

14

Kennedy, G. Classical Rhetoric and its Christian and Secular Tradition 2nd ed. Chapel Hill, NC, USA: U of North Carolina P, 1999, p. 14.

a See Engbers, s. "Branded: The Sister Arts of Rhetoric and Design." Art, Design, and Communication in Higher Education, 12.2 (2013), pgs. 149-158. "pin down" the effects of various formal design elements (e.g., color, font, size) on a universal audience (e.g., "The color black will produce these specific feelings and associations in audiences.") (p. 345). ${ }^{13}$ This kind of investigation is bound to end - as Schneller's does - in a failure of certainty. It recalls the use of "handbooks" of rhetoric that circulated in ancient Greece-documents that, in part, offered hard-and-fast strategies for engaging in good speaking, and listed both figures of speech and longer, more strictly structured speeches for students to memorize. Such systems simply do not account for the complexities integral to most systems of information delivery. In Classical Rhetoric and its Christian and Secular Traditions, George Kennedy notes that such "technical rhetoric" concentrated on the speech at the expense any concern for audience or sender. ${ }^{14}$ It is not that this kind of technical, even mechanical, approach cannot be helpful. Certainly, appreciating basic conventions and connotations of verbal and/or visual "grammar" is useful, and imitation is one important form of learning (through habit and repeated practice, we acquire wisdom and deftness of approach), but the rule-bound approach would not seem to be useful as the primary method for learning that would equip students to deal with the inevitable complexities involved in any communicative enterprise.

Instead, I suggest that the art of rhetoric - and specifically the scheme of the triangle-offers both a full, systematic theory and corresponding lines of inquiry for designers to consider as they develop their projects. Those questions might revolve around the three categories of proof-those related to sender, audience, and text (i.e., ethos, pathos and logos). The three categories - especially when embodied in triangular form — are simple and easy for students to remember as a touchstone, though as they deepen their understanding of the three types of proof, the analysis - and resulting designed projects - should become quite nuanced and complex. To be clear, I am not suggesting that such a process is unknown among design faculty and students, only that it could be used more widely, perhaps especially to consider the role of the sender, the element that is the most subtle and easy to overlook, especially for novice practitioners. ${ }^{a}$ Aristotle himself maintained that - in practice - the ethical appeal was the most persuasive. Thus, at the most basic level, students can simply be taught to be mindful of the three main components of any text: sender, audience, and text. At the next level, students can operationalize a set of standard questions they utilize to help them critically interrogate each component. For example: 
Re: the sender: Who are all the "senders" of this text? (e.g., in the case of the design of a hotel lobby, the sender might be the hotel company, the designer, and/or the city in which the hotel is located, etc.) How do the identities of those senders appear in this text? In what ways might those identities be at odds with one another and/or support one another? What improvements might be made in light of the answers to these questions?

Re: the audience: who are all the "users" of this text? What range of emotional and intellectual responses might this text invite in them? (It should be pointed out that this is a different question than analyzing the emotions that might be expressed by and/or through the text; for example, a man looking confident in an advertisement might actually invite opposing feelings - e.g., of intimidation or inadequacy - in its viewers.) How might those responses be shaped by the exigencies of time and other contextual factors? Are there more or less appropriate ways to design this text with those exigencies in mind?

Re: the text: What are the formal properties of the designed text (e.g., its layout, font, proportions, etc.)? How do the visual and verbal elements work to support the logic of the text? What other formal elements might add to the text's effectiveness?

Beyond this array of questions lies even greater possibilities for complex yet potentially fruitful inquiry, chiefly as it relates to investigations of the text, via logical appeals, and the sender, via ethical appeals. Analyses that address the audience's or users' roles seem to be the most well-traveled terrain for design students, who are accustomed to those kinds of investigations through coursework in, for example, the application of color theory or user-experience design. Rhetoricians would note the similarities that such investigations bear to pathetic, or emotional, analyses. Additionally, as a means to indicate the value of employing the lenses of the other two artistic appeals - logos and ethos-I will briefly describe two specific examples of these kinds of focused analyses.

Take, for example, the case of a hypothetical print advertisement for a toothpaste: with it, students may consider the various species of logical proof. The ad might include explicit verbal logic, such as Brand X, "brightens your teeth more effectively than leading competitors," and "it kills $98 \%$ of bacteria" 
and so on. The ad might, as well, include explicit visual logic - perhaps an image of a smiling woman with brilliant white teeth or a close-up of the product itself with its layers of "bacteria-fighting" agents made visible in some overt way. More subtly, though, students might observe implicit verbal logic-perhaps words with militaristic connotations (e.g., fight, depend, guard against, defeat, etc.) that imply, rather than directly support, the ad's argument. And, similarly, the ad might include images that suggest support rather than provide or facilitate it directly. Perhaps the ad includes recurring images of small shields to underline the theme of "defense." Or maybe the ad's use of a thick, bold typeface implies the fortified, sturdy nature of the product. That kind of investigation of logic - visual and verbal, explicit and implicit — can deepen and extend students' ability to invent and refine successful designs of all kinds that operate as fundamentally logical arguments, especially since they are not often conceived of as such.

With regard to ethical appeals - i.e., those focused on the sender - it is useful to get a bit more deeply into the details of the Aristotelean concept of ethos, which includes three components (of which one, two, or all three may be present): namely, the ways in which the sender conveys to the audience a sense of phronesis (prudence), arête (virtue), and/or eunoia (goodwill). Phronesis refers to the audience's impression of the sender as a person/institution of "practical wisdom" - perhaps authority, power, experience, savvy or some combination thereof. Arête might be better translated now as "likeability" or "relatability" - the audience's belief that the sender is like them —or admirable in some way. Finally, eunoia is the audience's feeling that the sender expresses care for them. In this case, I will use an actual example from the built environment: the well-known Apple Store on Fifth Avenue in Manhattan.

Designed by the architecture firm Bohlin, Cywinski, Jackson, the store opened in 2006, and as of 2017 , the building began major renovations

Anuta, J. "Apple is as savvy about real estate as it is tech: Why is Apple dismantling its glass cube? Because it can," Crain's New York Business, 26 April 2017. Online. Available at: http://www.crainsnewyork.com/article/20170426/ REAL_ESTATE/170429922/why-is-appledismantling-its-cube-because-thecompany-has-the-clout-to-be-a-player-in-retail-and-command-lower-rents (Accessed May 11, 2018). that, as of this writing in March of 2018, have yet to be revealed. ${ }^{15}$ The relatively small glass structure that has been present in this location for the past decade, however, is notably different from the tall, "traditional" buildings around it. When applying the questions prompted by utilizing the rhetorical triangle, one might theorize that the "sender" (i.e., Apple) expresses a certain power, authority, even chutzpah as a company with the means, first, to be located in such a prestigious spot - on Fifth Avenue, just steps away from Central Park - and on a space where it does not even appear as if there should be room for a building (and, in fact, the bulk of the retail space they operate in that 


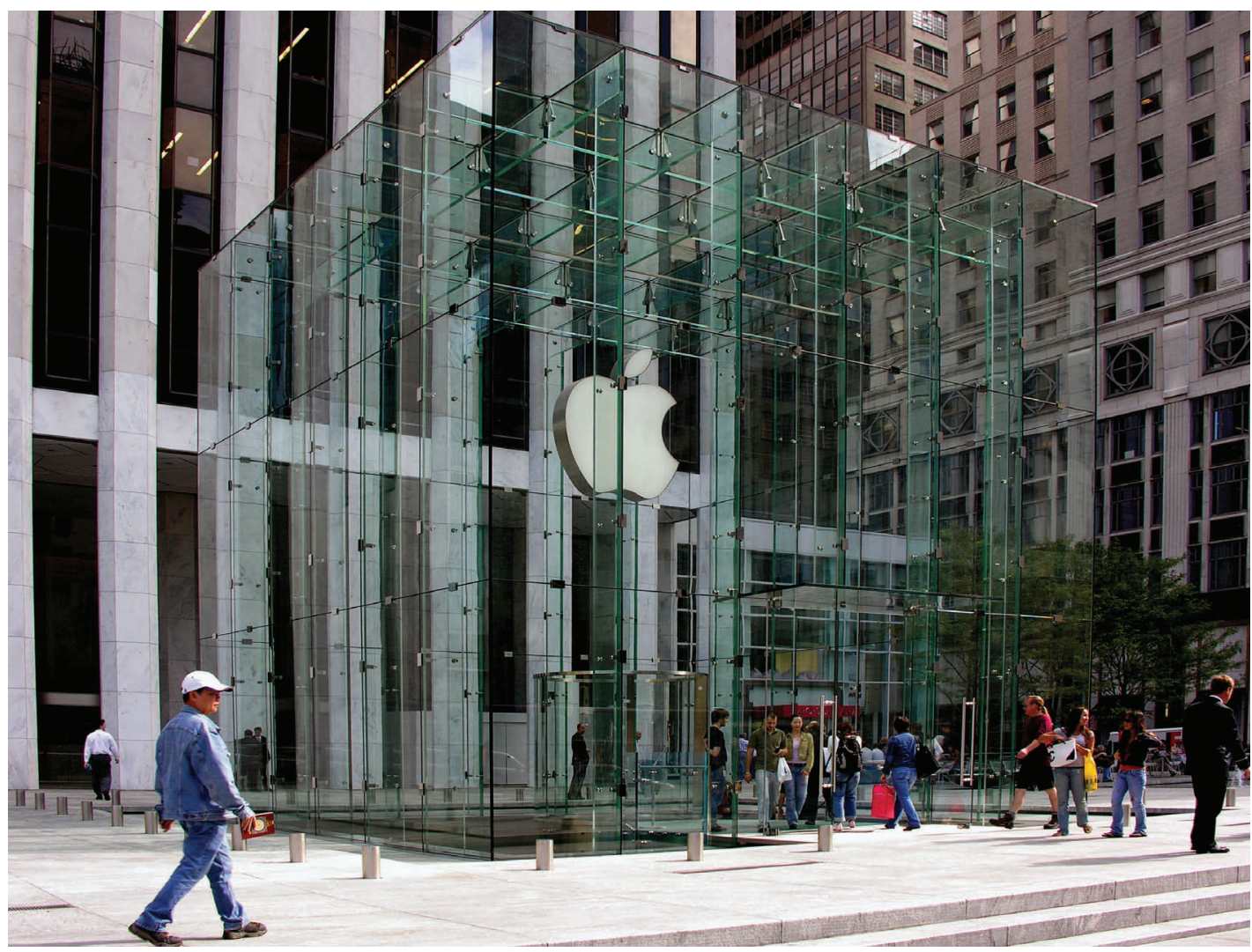

FIGURE 2: By Fletcher6 (Own work) [CC BY-SA 3.0 (https://creativecommons.org/ licenses/by-sa/3.0) or GFDL (http://www.gnu.org/copyleft/fdl.html)], via Wikimedia Commons.

location is subterranean). The building as text appears bold enough to bend the rules of zoning and conventions of design for its own purposes. Additionally, the building's transparency allows it to suggest a certain degree of compassion and care, given that its walls often seem to fade away, allowing, at some angles, the trees of Central Park, the blue sky, or the people on the other side of the building to be as apparent as much as, or more than, its walls. In this way, Apple as the sender may be seen to be deferential, a listener, a humble presence. The building's ethos suggests a sender that is simultaneously powerful (an aspect of phronesis) and humble (arête). Such design choices help to shape the rhetoric of the space so that it appears as an attractive, successful site for potential customers.

\section{Conclusion}

The rhetorical triangle provides the basis for an elegantly simple, yet still rigorous and systematic, process to support designers' analytical and creative practices. Equipping student designers with a scheme of concepts and associated 
${ }^{b}$ See Engbers, S. "Branded: The Sister Arts of Rhetoric and Design." Art, Design, and Communication in Higher Education, 12.2 (2013): pgs. 149-158. questions - grounded in a strong understanding of a specific theory-gives them a clear path toward thoughtful, rhetorically savvy work. An associated benefit of this process of inquiry is students' greater appreciation for designed objects as fundamentally communicative and, accordingly, quite similar to their written texts. Familiarity with such a process is also useful for faculty hoping to build stronger bridges between students' studio and humanities coursework. In my own case, mining the intersection between design and rhetoric has helped me teach writing concepts. For example, when I urge writing students to attend to audience (which involves accounting for their current base of knowledge, their preferences, their likely objections, their aspirations), I often point out the ways in which a designer has to take similar exigencies into consideration, whether dealing with readers, viewers, users, or some combination. Similarly, as I encourage students to consider the frequently-overlooked aspect of building their own character through language (i.e., their ethos), if I connect ethos (without making it merely equivalent) to the concept of "branding," they are more likely to see its relevance and importance. ${ }^{b}$ This kind of rhetorical practice has the power to inform both students' design work and their overall habits of writing and communication that are so necessary to the formation of adaptable and articulate citizen designers.

\section{References}

Anuta, J. "Apple is as savvy about real estate as it is tech: Why is Apple dismantling its glass cube? Because it can," Crain's New York Business, 26 April 2017. Online. Available at: http://www.crainsnewyork.com/ article/20170426/REAL_ESTATE/170429922/why-is-apple-dismantlingits-cube-because-the-company-has-the-clout-to-be-a-player-in-retailand-command-lower-rents (Accessed May 11, 2018).

Barnard, M. Graphic Design and Communication. London, UK: Routledge, 2005. Buchanan, R. "Declaration by Design: Rhetoric, Argument, and Demonstration in Design Practice.” Design Issues, 2.1 (1985): pgs. 4-22.

Corbett, E. \& Connors R. Classical Rhetoric for the Modern Student, 4th ed. New York, NY, USA: Oxford UP, 1999.

Davis, M. Graphic Design Theory. New York, NY, USA: Thames \& Hudson, 2012. 
Engbers, S. "Branded: The Sister Arts of Rhetoric and Design." Art, Design \& Communication in Higher Education, 12.2 (2013): pgs. 149-158.

Foss, S., Foss, K \& Trapp, R. Contemporary Perspectives on Rhetoric, 2nd ed. Prospect Heights, IL, USA: Waveland Press, 1985.

Kaufer, D. S. \& Butler, B. Rhetoric and the Arts and Design. New York, NY, USA: Routledge, 2013.

Kennedy, G. Classical Rhetoric and its Christian and Secular Tradition from Ancient to Modern Times, and ed. Chapel Hill, NC, USA: University of North Carolina Press, 1999.

Kinneavy, J. A Theory of Discourse: The Aims of Discourse. Englewood Cliffs, NJ, USA: Prentice Hall, 1971.

Schneller, A. "Design Rhetoric: Studying the Effects of Designed Objects.” Nature and Culture, 10.3 (2015): pgs. 333-356.

\section{Biography}

Susanna Kelly Engbers, Ph.D., is Professor of English at Kendall College of Art and Design of Ferris State University. She teaches courses in rhetoric, writing, and literature, and her research focuses on the visual and verbal rhetorical strategies of nineteenth-century American suffragists, narrative theory and design, and the intersections of visual rhetoric and design. Her work has been published in American Catholic Studies, Rhetoric Society Quarterly; the College English Association Forum; and Art, Design, and Communication in Higher Education. 